\title{
The experiences of metal fans with mental and developmental disorders in the metal music
}

\section{community}

\author{
Kyle J. Messick, Blanca Aranda, Chris Day \\ Coventry University
}

\begin{abstract}
A series of interviews were conducted to explore the experience of what it is like to be a member of metal music culture living with mental health conditions and/or developmental disabilities. Ten participants were interviewed, three of which had schizophrenia, four with autism spectrum disorder, two had bipolar affective disorder, and one had borderline personality disorder. Thematic analysis was utilized to explore the experiences of people living with various types of mental illness and developmental disabilities in the context of metal, which resulted in the development of three overarching themes. It was found that participants felt that the metal music community was more welcoming to them due to the broad use of lyrics about mental health topics and the prevalence of metal musicians that have mental health concerns. The broad application of mental health topics in metal was seen as having a de-stigmatizing effect towards mental health concerns, but at the cost of accuracy, as topics like schizophrenia are seen as fetishized and inaccurately depicted. Participants reported that the metal community affords its members with mental health conditions and developmental
\end{abstract}


disabilities a number benefits including a sense of belonging, the facilitation of mood maintenance, and the management of lesser symptoms. Symptom management appeared to be mitigated by symptom severity and influenced how participants experienced metal music.

\section{Keywords}

Mental illness, schizophrenia, autism, heavy metal, BPD, BPAD, belonging, stigma

\section{Introduction}

Metal music and its associated global musical culture began in the late 1960s and was characterized by a musical style that included loud volume, fast tempos, pounding percussion, and distorted guitars. Members of metal music culture generally share a common mode of dress, attitudes, symbols, and slang, although there are differences dependent on the particular metal subculture or community (Gross 1990). More recently, as metal music has become much more diverse since its inception, and as a growing number of scientists now empirically investigate it (Hickam 2014; Spracklen, Brown, \& Kahn-Harris 2001), it serves as an umbrella term that encompasses many unique subcultures that have differences in terms of moral reasoning styles, personality traits, affiliated musical styles, and preferred lyrical topics (Messick \& Aranda 2020). The individual subcultures that encompass the metal music community are generally each affiliated with a particular type of metal music, which can vary in terms of tempos, tuning, the use of musical dissonance, lyrical themes, song length, song structure, and 
vocal styles. For example, doom metal is a subgenre that is thought of as more somber, as it features slow tempos, elongated notes, and lyrical themes that often focus on human struggle. Doom metal frequently has a fanbase that has little overlap with fans of a disparate subgenre like death metal, which has fast tempos, less melodic musical structure, and aggressive lyrical themes. Members of metal music communities exist among all ages, social statuses, and occupations (Guibert \& Guibert 2016; Ury-Petesch 2016; Kahn-Harris 2007), and many metal parents pass the lifestyle down to their children (Guibert \& Guibert 2016). Although there is an increasing interest in investigating metal music communities scientifically, as doing so can bring a deeper understanding of sociocultural processes worldwide (Hickam 2014), there has not yet been much focus on mental health within metal music culture.

Prior to studies detecting differences in musical subgenre-dependent types of metal fans, metal music was often described as an intense form of counter-cultural music that was historically associated with sensation-seeking and arousal (Weisskirch \& Murphy 2004), and was oftentimes linked with deviance (Lynxwiler \& Gay 2000). Moreover, the music of heavy metal has frequently been affiliated with suicide, drug use, and other negative behaviors, however the relationship is not causal, as this musical preference and the associated aforementioned behaviors often reflect emotional vulnerability that is independent of metal fans' preference for metal music (Baker \& Bor 2008). Despite music therapy being prevalent (Gold, Voracek, \& Wigram 2004) and the existence of higher rates of mental illness within the metal community compared to the general population (Sabuncuoglu, Berkem, Akin, \& Imren 2012), very little research has been conducted on the experience of being a metal fan with mental illness, especially 
when it comes to the relationship between symptoms, music, and culture. There has been some documentation of metal music as playing a role in stress relief, but that study also mentioned the need for further research on the metal community's coping mechanisms and the development of preventative measures towards negative mental health consequences (Eischeid, Kneer, \& Englich 2019). Research has found that people with mental health conditions are especially attracted to metal music, as the overlapping themes of alienation present in many forms of mental illness and metal music create an emotional connection and a grounds for relatability and understanding (McKinnon 2011). These overlapping themes aren't limited to the lyrical content either, as rock and metal musicians also generally have higher levels of symptoms and disorders than those in other genres of music (Mason \& Daniels 2018). Lastly, just as the lyrical themes and musicians help form a more understanding cultural environment for someone with mental illness or developmental disabilities, so does the actual structure of metal music. As highlighted by Angeler (2018), people frequently draw parallels between the structures of heavy metal compositions and the symptoms of their disorder. For example, a song with many drastic musical changes can be likened by a person with bipolar disorder to how it feels to experience the highs and lows of being bipolar. Given the prevalence of mental illnesses and developmental disabilities in the metal community among fans and artists alike, we set out to explore the individual experiences of metal fans with these diagnoses. The aim of the present study was to explore the relationships that members of the metal community with mental illness and developmental disabilities have with metal music and the broader metal community. 


\section{Method}

\section{Participants}

Ten participants were recruited online through an open advertisement in metal-themed social networking groups. The advertisement specifically requested that participants were needed for a study exploring the experience of mental illness in the metal music community. All participants were adults over the age of eighteen years. Four of the participants were male and six of the participants were female. The participants reported first getting into metal between the ages of five and seventeen, so for participants that did not have symptoms since birth (as is the case of autism), their appreciation of metal music predated the onset of their symptoms. Participants reported becoming interested in metal music after being introduced to it by friends or family members. All of the participants came from a white ethnic background except for Malik, who is black. See Table 1 for a breakdown of each participant, their diagnosis, and the symptoms associated with that condition as outlined by the DSM-5 (Diagnostic and Statistical Manual of Mental Disorders). Each participant self-reported the diagnosis that they had received from a medical professional. Three participants (Sarah, Laura, and Malik) reported having been diagnosed with schizophrenia (SCZ). Two of the participants (Amanda and Franz) reported being diagnosed with bipolar affective disorder (BPAD). One participant (Tasha) reported being diagnosed with borderline personality disorder (BPD). Three participants (Thomas, John, and Sergio) stated they have autism (ASD), and one participant (Varun) stated that they have Asperger Syndrome (AS). Please note, the DSM now considers Asperger Syndrome to be collectively encompassed under Autism Spectrum Disorder, so this article will use ASD when generalizing to Asperger 
Syndrome. All participants were culturally Western, as they lived in either the United

States or Europe. No further identifiers were collected to maintain the anonymity of participants, and pseudonyms were used to facilitate reporting while further protecting anonymity.

\begin{tabular}{|c|c|c|}
\hline Participant & $\begin{array}{l}\text { Mental } \\
\text { Illness/Developmental } \\
\text { Disability }\end{array}$ & $\begin{array}{l}\text { Defining Characteristics } \\
\text { according to the DSM }\end{array}$ \\
\hline $\begin{array}{l}\text { Laura } \\
\text { Malik } \\
\text { Sarah }\end{array}$ & Schizophrenia(SCZ) & $\begin{array}{l}\text { Schizophrenia is a severe } \\
\text { mental health condition that } \\
\text { can encompass a wide variety } \\
\text { of symptoms, including } \\
\text { delusions, hallucinations, } \\
\text { disorganized speech and } \\
\text { behavior, and other } \\
\text { symptoms that can cause } \\
\text { social or occupational } \\
\text { dysfunction. }\end{array}$ \\
\hline $\begin{array}{l}\text { Amanda } \\
\text { Franz }\end{array}$ & $\begin{array}{l}\text { Bipolar Affective Disorder } \\
\text { (BPAD) }\end{array}$ & $\begin{array}{l}\text { Bipolar disorder involves } \\
\text { going through intense } \\
\text { emotional changes that differ } \\
\text { from a person's usual mood } \\
\text { and behavior. }\end{array}$ \\
\hline Tasha & $\begin{array}{l}\text { Borderline Personality } \\
\text { Disorder (BPD) }\end{array}$ & $\begin{array}{l}\text { Borderline Personality } \\
\text { Disorder is characterized by a } \\
\text { pervasive pattern of } \\
\text { instability of interpersonal } \\
\text { relationships, self-image, and } \\
\text { affects, and marked } \\
\text { impulsivity beginning by } \\
\text { early adulthood and present } \\
\text { in a variety of contexts. }\end{array}$ \\
\hline $\begin{array}{l}\text { John } \\
\text { Sergio } \\
\text { Thomas } \\
\text { Varun }\end{array}$ & $\begin{array}{l}\text { Autism Spectrum Disorder } \\
\text { (ASD)* } \\
\text { *Asperger Syndrome is now included in } \\
\text { this definition according to the DSM. }\end{array}$ & $\begin{array}{l}\text { Autism spectrum disorder is } \\
\text { characterized by persistent } \\
\text { difficulties with social } \\
\text { communication and } \\
\text { interaction, and by restricted } \\
\text { and repetitive patterns of } \\
\text { behaviors, activities, or } \\
\text { interests. }\end{array}$ \\
\hline
\end{tabular}

Table 1. Synopsis of participants, diagnoses, and definition symptomology

\section{Procedure}


A call for participants was advertised on a social media platform specifically targeting fans of metal music that were living with mental health or developmental conditions. Participation in the study was voluntary, and participants were made aware that they could withdraw from the study at any time without explanation. None of the participants received compensation, and there weren't any anticipated risks or benefits. Participants were asked a series of questions that they could respond to either through text responses or by sending recorded audio responses to the researchers, which were then transcribed prior to analysis. The optional approaches were offered to address the discomfort that can be typical of autism spectrum disorder and other conditions.

\section{Materials and Method}

The interview schedule was prepared in advance and consisted of twelve open-ended questions following a semi-structured schedule that was tailored to the individual's condition/diagnosis (e.g., Does metal music ever help you cope with autism, or manage any symptoms of it?). The questions explored various topics regarding the experiences of having a mental illness or developmental disabilities in the metal community including the acceptance of mental/developmental conditions in the metal community, and metal music and the metal community's perceived role in coping with symptoms, if any. At the end of the interview participants were asked if they had any questions or anything else they would like to discuss and were then thanked for their time. The interviews were converted into organized transcripts and were analyzed using thematic analysis.

\section{Analysis}

In the interest of providing a transparent and replicable methodology, this study utilized the analytic approach outlined by Braun and Clark (2008), which provides a series of 
well-defined phases that researchers should follow in order to produce a comprehensive thematic analysis. This study aimed to understand and capture the actual lived experience of people identifying as metal fans who have a self-reported mental health condition or developmental disability and how they make sense of their experiences within the metal community and outside of it. Due to the nature of the research question, this study utilized an essentialist/realist stance with the assumption that experiences and meanings are expressed through language and thus we focused on the explicit meaning in the data in an attempt to understand and explain the experiences, meanings, and realities of individuals living with mental illness who are part of the metal community.

In accordance with the procedure delineated by Braun and Clark, the data were first transcribed and subsequently read multiple times to gain familiarization. Codes were carefully identified and written to reflect the participant's original words. Similar codes were then grouped together to form potential sub-themes, which were further reviewed to ensure coherency and consistency with the original data. Any themes that were not substantiated by the data, or that were repetitive, were removed or combined with other themes. The sub-themes were then reviewed, again, to ensure agreement with the original data and finally combined to form the overarching themes of the research as presented. This process was performed by each of the researchers and then cross-referenced to improve the accuracy of the identified themes and the analysis through inter-rater reliability.

\section{Results}

Through the analysis we created the following three main themes: 'The Inclusion of Mental Health Topics in Metal Culture', 'The Relationship between Emotion, Symptoms, 
and Music', and 'The Search for Understanding and Belonging'. The first theme serves to establish the environment in which mental health is approached in metal music culture, the second explores the relationships between emotionality, symptomology, and metal, and the last theme discloses how metal music culture moves people with different mental health diagnoses towards a feeling of understanding and belonging. It is important to mention that the authors acknowledge the complexities and diversities of mental health conditions and developmental disabilities and especially the individual differences among participants and how they manage and express their symptoms. Our aim is not to make generalizations among all mental health conditions and developmental disabilities, but to draw attention to the everyday experiences of people who have mental health conditions or developmental disabilities and are a part of the metal community. There are similarities across different conditions, but there are also differences - particularly when it comes to more severe symptoms - which will be noted in the results section.

\section{The Inclusion of Mental Health Topics in Metal Culture}

This theme identified four ways in which mental health as a topic and mental health conditions are presented within metal cultures and the effect this has on people within the metal community who have mental health conditions and developmental disabilities. We highlight the thoughts and opinions participants have regarding the presence of mental illness in metal music. These subthemes include: 'The Relatability of Metal Music and Artists', 'Parallels between Symptoms and Musical Structure', 'The Use of Mental Illness for Creative Effect in Metal Music', and 'Reduced Stigma of Mental Health Conditions within Metal Music Culture'. This theme outlines the perceived contextualized relationship between the metal community and mental health topics. 


\subsection{The Relatability of Metal Music and Artists}

Metal lyrics often include lyrical themes about human emotional struggles, and metal musicians often struggle with mental health concerns themselves in a very public way. These contribute to the relatability of metal music and metal musicians for people with mental health conditions. For example, Tasha (BPD) expressed how important lyrics about struggle are to her: 'bands like Opeth, Katatonia, and Mastodon are the bands I got when I am severely depressed. Their words [lyrics] are relatable and I don't feel as alone in this battle of life'. John (ASD) embraced a different type of metal music, but maintained a similar focus on relatability with human experience: 'Sludge [a subgenre of doom metal] is very dark and nihilistic at times and that kind of matches how I see the world'. The candour with which emotional struggle is expressed in metal culture, which extends to mental health concerns, seems crucial to the embrace of metal music and culture by individuals with different mental health diagnoses.

It was noted by five out of the ten participants that metal musicians are often open about their struggles with mental health conditions, as was expressed by Amanda (BPAD): 'I know through lyrics and interviews that there are probably quite a lot of metal performers who suffer from some form of mental health issues, which makes me feel it's easier to relate to the music in some ways'. They also note that in certain subgenre scenes mental health conditions are openly discussed, as Laura illustrated: 'In more extreme subgenre scenes like noise and sludge it's [mental struggles] often discussed candidly'. This sincerity and openness about mental health struggles appeared to serve as a motivator for some participants, as was the case with Laura who stated, 'I remember finding out that Sylvain Houde [from Canadian death metal band Kataklysm] 
was schizophrenic which gave me reassurance to embrace my artistic visions and solace knowing he at least made it through 7 years of being in a touring band' (Laura SCZ).

What seems important here is that the openness and transparency regarding mental health conditions and struggles within the metal cultural context and community affords its fans a sense of relation and in some instances, this serves as a source of motivation and comfort from knowing that other people are going through the same mental health journeys. Sergio described it very well when he stated:

I think a lot of metal songs are relatable to a lot of people with all kinds of mental disorders - I don't think it is necessarily what the musicians set out to do, but I think because of the uniquely introspective style of metal, there's a lot more to relate to for people with any type of mental or life issue. I think sometimes just hearing somebody you've never met from somewhere else in the world put into words what's going on with you can be great encouragement to keep going.

\subsection{Parallels between Symptoms and Musical Structure}

The relatability between mental health concerns extends beyond lyrics and musicians, as participants also described parallels between their symptoms and the musical structure of metal songs. The intensity of symptoms, particularly ones that can change suddenly or are experienced intensely, can be likened to the changes and intensity in metal music. Participants described the ways in which music had a resemblance to some of their symptoms, which increased their inclination towards metal music. For example, mania, a hallmark symptom of bipolar disorder, where one experiences elevated moods, euphoria, over-activity, lack of sleep, and increased optimism (Belmaker 2004), was likened to a 
specific type of subgenre of music by Franz, who has bipolar disorder: 'I'm more partial to the noisier and more violent subgenres, mania tends to go hand in hand with the themes they present. Quite partial to black, death, thrash, sludge and so on, and my taste is very dark.' He further went on to use mental illness terminology to describe the sound

of bands that prominently utilize musical dissonance: 'I'd describe groups like Deathspell Omega as schizotypal, and mildly psychotic' (Franz BPAD).

Another participant expressed that she actually needed the music to sound like her fight against some of her symptoms: 'I needed aggression. The music sounded like my fight against my hallucinations and demons' (Sarah SCZ). These responses are consistent with previous claims that people find parallels between the structures of heavy metal music and the symptomatology (Angler 2018).

\subsection{The Use of Mental Illness for Creative Effect in Metal Music}

It isn't that metal culture just makes mental health concerns relatable, it also tends to embrace mental illness, to an extent that often exaggerates mental health concerns for creative effect, but embracing these topics also makes them less taboo, and potentially less stigmatizing. Many participants noted the ways in which metal music and culture are attracted to mental health conditions: 'I think metal music is attracted to a lot of mental illness symptoms. I mean this in a very broad sense. And to boot a lot of noteworthy metal musicians have suffered/dealt with their own illness. There is an appeal, for sure' (Sarah SCZ). Participants described a cultural fetishization towards schizophrenia in particular. For instance, Laura mentioned that 'metal has a sort of explicit fetish for schizophrenia which I don't mind that much as it doesn't permeate into stigma' (Laura $\mathrm{SCZ})$. 
Participants seemed well aware of the use of mental illness in the metal community for creative purposes stating that, 'It seems many artists employ things like this [mental condition] for shock value or out of macabre fascination' (Franz BPD). Ways in which bands use these symptoms as lyrical topics were described with detail:

Death metal band Cannibal Corpse has a song called Psychotic Precision. It's about a psychotic murder if I read the lyrics well. Psychosis are horrid. They use it for lyrics [...] metal usually has a dark theme, so it's obvious they use mental conditions as well for a lyrical theme (Malik SCZ).

The participants didn't seem to be particularly offended by the use of mental illness and its symptoms for creative effect:

Like I said, metal sort of fetishizes schizophrenia as a tie to insanity. It's not really accurate but I don't see it as harmful since the songs are more of a vague painting of the disorder as opposed to it being an aspect of murder or something (Laura SCZ).

However, participants did express some caution with regards to how mental illness is 'glamorized' in the metal community while not being based on real, personal experiences:

Metal is attracted to a lot of mental health based symptoms. Psychosis, paranoia, depression, violent fantasies. I don't think it's as clear as being good or bad. I'm cautious of people who glamorize these conditions with nothing based in reality or their personal experience. So I like that it could 
theoretically relate to me and be a safe spot but I think a lot of it is image driven' (Sarah SCZ).

\subsection{Reduced Stigma of Mental Health Conditions within Metal Music Culture}

Following the aspects of relatability and the embracing of mental health conditions through aspects of metal culture, this theme illustrated how those characteristics can lead to reduced stigma towards mental illness in metal culture compared to the general population. This last section of the current theme outlines the way that the presence of mental health conditions in metal culture serves an informative function to some: 'I think being into metal, at least tangentially, let me know what schizophrenia was like so when the symptoms onset, it wasn't entirely frightening and I don't think there could be anyway I could've gotten into metal before the other disorders manifested' (Laura SCZ). Further, mental health topics being addressed in metal culture were claimed to promote healthy discussions about mental health:

I think suicide and depression can be quite a common theme in metal. Bands like Megadeth for example, have written a few songs....that seem oriented around mental illness [...] Judas Priest did "Beyond the Realms of Death.” Ozzy did "Suicide Solution", "S.I.N", "Flying High Again”, "Can You Hear Them?" and others related to mental health issues. It seems to me that with such big names mentioning it, whether it's their experience or not, it promotes a healthy discussion about mental health in the community (Amanda BPD).

Inclusive of the mixed feelings expressed by participants regarding the use of mental illness, specifically schizophrenia, it seems that overall the presence of mental 
health conditions within the metal context had a positive effect and was found to be useful in a number of ways, primarily by making mental health conditions a topic that, for some, are no longer taboo to talk about. In this theme we highlighted the reported prominence of mental health conditions present within the metal community, not only within the music, but also within the people who make up the community - both fans and artists alike. Furthermore, it highlighted the ways in which the open presence of mental health topics in the metal community provide its members who share mental illness or developmental diagnoses with a sense of relatable connection to the music, the artists, and other fans, which in turn provides people experiencing mental health conditions with a motivation to carry on their daily lives or their career goals, and provides a space where topics that may be taboo in some settings can be freely talked about and shared, even if the information about those topics isn't always accurate.

\section{The Relationship between Emotion, Symptoms, and Music}

This theme draws attention to the relationship between metal music, emotions, and symptoms of mental health conditions and developmental disabilities. While some participants noted some of the ways in which their mental health condition or developmental disability enhanced their musical experiences, what was more prominent were the ways they used metal music to cope with the daily struggles that came as a result of their developmental disability or mental health condition, but with some limitations. This is covered in across five sub-themes: 'The Compounding Experience of Symptoms and Music' 'The Role of Metal Music in Managing Emotions', 'Metal Music's Role in Symptom Management and Alleviation', 'The Role of Symptom Severity', and 'The Importance of Social Support'. 


\subsection{The Compounding Experiences of Symptoms and Music}

This section outlines the ways in which participants' mental health symptoms or developmental disability characteristics influenced, enhanced, or differentiated the ways that participants experienced music compared to 'other' people. Some participants expressed intensified experiences or sensations while listening to music as a result of their mental health or developmental disability symptomatology. For example, Malik described his experience listening to black metal as being amplified during a pre-psychosis stage of his schizophrenia, which he hadn't initially realized that it might have made his experience of the music different from other people:

Metal with schizophrenia is intense. I'm a black metal fan by heart [...] the music is so much more alive when you are in a pre-psychosis stage of your schizophrenia. It was fun and I enjoyed it. I thought it was normal and everybody experienced black metal the same way.

Other participants also described experiencing music and various aspects about music differently. Thomas (ASD) stated a preference for a specific subgenre because the complexity of the music creates a focusing effect for him that can distract from any social discomfort: 'I love prog [progressive metal] in the way that it really makes me feel like I can use every part of my brain to analyze the music, the same with tech death.' He went on to add 'Being at a live concert with my friends is one of the best experiences I can ever go through[...]because I can tunnel-vision on the music and completely forget that I am in a crowded atmosphere.' Further, he described how he uses some classic 
characteristics of autism, at least in his perception, to his advantage in the metal community for acquiring and maintaining metal encyclopaedic knowledge:

People know about the whole autistic special interest kind of deal, and, basically, there $[\ldots]$ are still a lot of large people that know the entire genre like the back of their hands with the autism spectrum because of $[\ldots]$ the stereotypical memory boost, which I've definitely felt myself, and I put to use. I know almost every death doom band, because that's my genre of choice, for example.

And when asked if he thought people knew he had autism without him disclosing, he made it clear that being on the spectrum afforded him different ways of experiencing music:

I feel my reputation has made it so that it's very clear that I have autism, but the way that I speak about it, the way I clearly analyze the music in a different way than many other people do, I feel that people pick up on that if they can't tell it's the autism.

\subsection{The Role of Metal Music in Managing Emotions}

Participants reported using metal music to help them cope with many different aspects of their physical and mental well-being, in particular when it comes to mood maintenance. Overall, participants reported using metal to help center themselves when they felt overwhelmed:

Metal music is actually pretty much my number one coping mechanism. My go-to response for not having, not knowing what to do or being 
overwhelmed, is putting on some music. In fact, my favorite bands are pretty much the ones that help me cope the most (Thomas ASD).

Music was used to ease negative emotions that participants experienced: 'I could just lay down and get lost in the music, and soon everything feels a little bit better' (Tasha BPD). Often times they described listening to specific subgenres of metal music that they felt corresponded with the management of particular emotions. Participants used the music to cope with these emotions and further described the musical qualities that music in these styles had that made them a helpful coping mechanism, illustrating that musical subgenre preferences play an important role in coping:

Certain genres are more helpful than others depending on what I'm using it for. Something like an aggressively themed grindcore, thrash, death metal, or street punk album can be very helpful when I'm frustrated or angry and need to vent a little. Whereas something like atmospheric black metal is useful when I'm trying to keep calm and relax[...]I've also used a lot of forms of metal, black metal, NWOBHM [new wave of British heavy metal], folk metal, to name a few, to help me feel more confident when I'm feeling withdrawn (Sergio, ASD).

Participants predominantly used metal music to assuage certain emotions they were feeling, as Tasha (BPD) expressed:

If I am depressed, I listen to Opeth and Katatonia [bands that are characterized by beautiful melodies and slower tempos]. The way their music is composed, it is peaceful to me, and it puts me into a meditative state. When I am angry, I 
prefer listening to death metal [aggressive music with fast tempos] and just scream the lyrics at the top of my lungs while I headbang around the house.

Tasha describes using different types of music for different forms of mood maintenance. In one she describes a more meditative function while the other serves as what might provide a cathartic function where she can let out her anger. She described both as being helpful for managing her emotions.

While using metal music to manage emotions was a prominent function of metal music for these participants, a few participants also mentioned that sometimes, metal music also serves as a way to release any excess physical energy they feel, such was the case with Thomas, who is on the Autism spectrum, who explained his experience at live metal concerts: 'I can really, physically, unleash myself to do whatever bodily needs I need, especially because I crave exercise a lot, I need to be moving around a lot, so I find that experience to be one of the best things there is'. Conversely, metal music was used by participants to provide a boost of energy:

The intensity of the beats and the speed of the guitars pumps me up. It helps me work out all the aggression that I was feeling. Even when I'm in a great mood I will listen to death metal. It's just so fast paced and fun. It gets you going! (Tasha BPD).

It should be noted that all of the participants had different metal musical preferences, so which types of metal and which bands were most useful and important to them was diverse and had little overlap, so generalizations should not be made based on the specific bands or musical subgenres that participants embraced. These effects would be dependent on musical preferences. However, their experiences suggest that there are commonalities 
in the role of musical tempos and the emotions that these are connected to. In that, slower tempos and melody feature in the experience of more lethargic and serene emotions (Coggins 2016) such as sadness and feelings of transcendence, whereas faster tempos connect with, or facilitate, the more energetic emotions such as anger and excitement, which supports findings on arousal and emotion processing as a result of listening to music (Sharman \& Dingle 2015).

\subsection{Metal Music's Role in Symptom Management and Alleviation}

In addition to using metal music to manage emotions, a common pattern among participants was the use of metal music to alleviate self-destructive urges such as selfharm, as was the case with Tasha (BPD): 'I have certain genres for certain moods. If I am feeling the urge to self-harm, I'll listen to metalcore [...] Metalcore to me is both angry, yet melancholy, which is both the emotions I feel when I feel like relapsing and selfharming'. Sarah (SCZ) gave this notion further credence: 'High energy music helps. Be it punk, metal, anything aggressive. It's kind of a way to get out some feelings without acting on certain urges, violent fantasies, cutting, even excessive crying.' Other participants noted how metal music helped them combat a drug or alcohol relapse for example, Varun (ASD) explained:

Metal has helped immensely with dealing with depression and Asperger's.

One such example, was after my great grandfather had passed, I felt depressed and was very close to falling back into old vices, drinking and self-mutilation, and a certain song came on, and it served as a catharsis.

It was clear that metal music often served an alleviating function during times of distress for participants, and this also extended into other mental processes as illustrated by Laura 
(SCZ): 'Avant-garde/experimental metal really helps me return to normal during dissociation. The rich complexity of it keeps my brain from continuing its dysfunctional thought pattern.'

\subsection{The Role of Symptom Severity}

While the majority of the participants said that they use metal music to cope with their symptoms, this wasn't true for every participant. One participant acknowledged the severity of their symptoms and acknowledged that, although metal music and culture is an important aspect in their life, it will not help with the more severe aspects of their mental health condition. For example, Malik explained that music does not help him cope with the symptoms of schizophrenia, 'No it [metal music] does not. Schizophrenia exceeds that. It cannot help you cope with stuff because it's so overwhelmingly strong.' He also responded in a similar way when asked if being at concerts or with friends helped manage his schizophrenia in any way, 'No it does not, I need my medication and frequent visits to my social worker. That is the only way I can manage it. But the medication is one of the most important factors.' It seemed clear that for Malik, while an avid metal fan who had stated that schizophrenia amplifies his experience of metal, his schizophrenia was too strong to be influenced by metal music and culture in any coping or managerial magnitude.

\subsection{Role of Social Support}

Another prominent aspect of coping that was mentioned consistently was the importance of social support during times of distress. Earlier sections of this theme outlined the importance of music in mood maintenance, but this section specifically addressed the role of the metal community. In this section we highlight the various ways in which having 
social support during times of distress was greatly helpful to our participants: 'Having awesome people there for me has pulled me out of the worst [anxiety] attacks' (Amanda BPAD). Some social situations might trigger anxiety attacks, but people can assist in the alleviation of those symptoms:

It doesn't always help me to be in large public spaces as it can trigger anxiety. However, I recently experienced an anxiety attack at a [metal music] festival and my friends accepted that I had anxiety as soon as I said it. They offered me gum and a drink to calm down, and it worked. Knowing I was with people who understood and didn't judge helped more than anything has before (Amanda BPAD).

Overall, a common notion was that having members of the metal community around was helpful in grounding participants and easing some of their symptoms or attacks: 'I would say just being around people in general helps. When I am at shows I can bounce off the energy and it is a little therapeutic' (Sarah SCZ). Amanda (BPAD) further reinforced the important of social support by making a call for assistance emphasizing the importance of helping others, 'If you know somebody struggling with anxiety, then please be as supportive as possible. Having awesome people there for me has pulled me out of the worst attacks.'

\section{The Search for Understanding and Belonging}

Taking into consideration the prevalence of mental health conditions and themes in metal culture and the influence it has on metal fans that are a part of the metal community, we wanted to highlight three aspects that were readily communicated by the participants: the desire for understanding, belonging, and acceptance from others. In this theme we 
identified five sub-themes that reflect these desires and the ways in which participants felt those needs were addressed. These include 'Seeking Understanding', 'A Sense of Belonging'. 'Perceptions within the Metal Community', 'Feigning Normality' and 'Perceptions Outside of the Metal Community'

\subsection{Seeking Understanding}

When participants were asked if there was anything else that they would like people to know about living with a mental illness or developmental disability, Participants were quick to express a desire to be understood by society as a whole. Some responses were succinct:

People with BPD only want to be loved and accepted like everyone else. Just be patient with us as we are trying to figure out how to feel normal again when we are coming down from extreme mood swings, and just listen to and remind us that you are there. That's one of the characteristics of BPD, we fear abandonment (Tash BPD).

Some were more subtle and expressed their personal experiences while including information about their mental illness or developmental disability, in order to dispel misconceptions and myths. For instance, Laura described her personal experience with the hallucinations that accompany her schizophrenia:

Schizophrenia doesn't work like it's painted to work at all and my hallucinations occur infrequently and are often benign like seeing fireworks in the sky or bugs that are not there. People forget the paranoid delusions aspect of it which affects me more than the hallucinations. 
Sergio explained a common misconception about people who have autism:

One of the things I think people don't grasp about autism, and indeed many types of mental problems, is that you can't assume consistency. If I'm okay with a situation at first, that doesn't mean I'll remain that way, and I won't necessarily know what brought about the change. It's pointless to say things such as "you were fine with $\mathrm{X}$ a moment ago" ... because most people with mental conditions are highly changeable through no real fault of their own... people are people. You shouldn't view people with autism, or any disability, as some eldritch mass of condition floating around with a face glued to it. We're exactly the same as you and your friends, we just have problems you don't necessarily have... just treat us as you should anyone, with respect and understanding, not judgement and a "mother-knows-best" attitude.

Consistently, their narratives expressed a desire for acceptance, love, and understanding, and this didn't seem to be aimed strictly within the metal community but extended to the general population too.

\subsection{A Sense of Belonging}

We outlined that participants often desire to fit in and be understood, both of which can play into a desire for belonging. Many participants found this sense of belonging within the metal community, which provides support for the notion that it is a community that associates fewer stigmas towards mental health conditions. For example: 
At the time of developing symptoms of bipolar disorder, I actually didn't take much time for music or anything that I enjoyed. Actually getting back into metal a year or so later and having friends who were into it has helped my mental health more than anything else because I feel more accepted. I don't feel like I have to do anything to fit in apart from being myself (Amanda BPAD).

Participants also reported that metal music can bring a sense of belonging: 'Metal music helps me connect with my emotions and makes me feel that I'm not alone, that there are others that understand going through the struggles of life' (John ASD). Even without acting in a social way, being present at a metal concert brought them a sense of belonging: 'Even if I decide not to talk to anyone else at the show, I always feel like I belong. It always feels like home' (Tasha BPD). Being in a metal context in particular was important: 'I think I'm so much more at home at a festival surrounded by metalheads as opposed to a popular night club' (Amanda BPAD). The metal community, including the people, music, and environment, all seem to provide the sense of belonging that participants sought after.

\subsection{Perceptions within the Metal Community}

Overall the consensus seemed to be that the metal community is more tolerant of mental health conditions: ' $[\ldots]$ the metal scene in general tolerates many things that are completely unacceptable in society, and that extends to this [mental health condition]' (Franz, BPAD). Furthermore, participants expressed feeling welcomed in the metal community regardless of any mental health conditions they may have: 'Being around the metal community has felt more welcoming than any other group I have ever met' (Tasha 
BPD).

Some even likened the metal community to a family more so than a group of friends: 'Metal fans have been really accepting of my diagnosis, and are there when I need them the most... When it comes to the metal community, it feels more like a family bond than it does a friendship. We are all there for each other.' (Tasha BPD). This acceptance was extended to other mental health conditions and other cognitive or developmental disabilities such as autism, as described by Varun:

I'd not say that Asperger's syndrome or depression hold too much weight. I haven't really encountered much stigma among metal fans for it, the few that I have discussed it with. I do feel more accepted among the metal community, at least online, than I do with most people in general.

Varun drew an interesting distinction when he mentioned the online metal community, indicating that he might be primarily engaging with and maintaining his relationship with metal culture through social networking sites, rather than through a devoted community in the area that he lives, and that online interaction serves an important function for feeling accepted.

\subsection{Feigning Normality}

One participant explained their reasoning for the perceived general higher acceptance rate of disabilities and illnesses of any kind in the metal community by drawing a parallel between mental health stigmas and the general negative stigmas assigned to fans of metal music: 
I think there's always going to be some form of stigma, but it's a lot lot less in the metal community[...]The metal community faces criticism and its own stigmas and I think that's why it's a lot easier for metal fans to understand (Amanda BPAD).

Contrastingly, it did emerge among a couple of the interviewees that they acted 'normal' in certain social situations despite what may actually be going on within them. In this way, they feigned normality to avoid drawing unwanted attention to themselves, their symptoms, or their true experiences. When Sarah was asked if she felt people knew she had schizophrenia without her making them aware she responded:

I am a fantastic actor. I'm a favorite at parties. I can walk the walk and talk the talk. Sometimes I feel it slipping through and I feel like I'm cheating but those close to me definitely pick up on symptoms and sometimes experience the fallout.

Franz expressed a similar experience:

I'm bipolar, but when in extreme episodes of psychosis, having people around helps me stay grounded, even if I believe on some level that they are conspiring against me I can still function as my mask, and you need other people to regulate affect, meet social needs, and find stimulation.

Therefore, even though the metal community was felt to be a place of acceptance and inclusivity, there isn't always the freedom to be open at all times. It may be that this was a form of personal protection against stigma, a way of protecting 
others from 'the fallout' or the desire to belong and not be seen as 'other'. This may be informed by experiences of reactions from general society, which is explored in the next theme.

\subsection{Perceptions Outside of the Metal Community}

While participants expressed feeling a sense of belonging in the metal community, we wanted to further explore this theme in a more general sense. In this subtheme we gathered the points in the interviews where the participants drew distinctions between how the metal community and the general population diverge in regards to mental health conditions, specifically to how the participants are treated by and the reaction of those to whom they disclose their mental health status.

The sentiment was different when it came to how the participants felt the general population reacted to mental illness. Laura (SCZ) stated, 'Mainstream society definitely has an open stigma against any mental disorder.' Many participants spoke openly about their personal experience with negative reactions from the general population, for instance, Tasha explained how people react when they find out she has borderline personality disorder: 'Normally people start treating me differently once they find out that I have BPD. Even more so if they research BPD and see the characteristics that come along with BPD.' When Malik was asked how people react to finding out he has schizophrenia he replied that people in general react 'shocked and frightened'. Some participants told of instances where their specific mental illness was used as an insult. Amanda 
described one such incident when asked how people generally respond to learning she has BPAD:

Usually they'll mention their own experience but it's usually got some ignorance behind it. Like for example, a friend of mine used bipolar as an insult about a girl right after I'd informed her of my mental illness. It seems if it doesn't touch somebody's life, they choose to stay wilfully ignorant, but I think that is true about a lot of things.

It's important to note that this distinction between the metal community and the general population wasn't as clear-cut as described above. There were a few instances where participants noted no such difference in treatment between the general population and the metal community. And while this was less predominant of an occurrence throughout the sample, the authors felt it was still important to include such instances. John reported that he is sometimes reluctant to tell even metal fans that he has Asperger's for fear of stigma, and explained that the stigma might actually be about the same in both populations:

I did have a bandmate that made an offhand comment that people with Asperger's have no filter but he was unaware that I have Asperger's [sic]. He felt bad once I pointed it out. I had a similar situation with a non-metal friend who made a comment about autistic people being, in her words, retarded, and felt bad when I called her out. So I guess the stigma is about even.

Another participant mentioned that the stigma is everywhere stating: 
So honestly whenever I go on like any part of the internet, one of the go-to insults people will try to, uh, shove at someone, is autism. You know, all of the sudden, you'll be compared to fedora-wearers, anime fans, stuff like that. People love to toss around the word autism without truly understanding what it means... (Thomas ASD).

Thomas explained that he uses this prejudice as a way to filter out people in his life who he felt he was better off without:

I actually really like to tell people that I have autism because I see it as some sort of acid test, the people that started treating me differently, those are the people that, that basically tells you what people I shouldn't associate with - which people are douchebags - which people I should distance myself in life from, so I'm actually glad that for some people it does, just because I can learn they're just a shitty person without having to waste my time, efforts and optimism on a temporary friend only to realize that they are not someone I want to be friends with.

While a couple of the participants described having had negative encounters both within and outside of the metal community when it came to their mental or developmental conditions, the majority felt far more accepted within the metal community than in the general population.

\section{Discussion}

This study aimed to explore the experiences of people with mental and/or developmental conditions who are a part of the metal community through multiple facets and the 
interplay between themselves, music, and the metal community. It was found that metal music culture has an environment that feels welcoming for people with mental health disorders because the lyrical content of metal songs often incorporate mental health topics, and metal musicians often have open struggles about their own mental health disorders. This incorporation of mental health topics through lyrics, musicians, and discussion is seen as having a de-stigmatizing effect that allows for lower perceived levels of prejudice compared to what members of the metal community have experienced outside of metal culture. The lower perception of stigma towards mental health concerns in the metal community is an important one, as personally held and perceived community stigmas are associated with negative attitudes towards help-seeking (Wrigley, Jackson, Judd, \& Komiti 2005; Amato \& Bradshaw 1985; Kushner \& Sher 1991). The relatability of metal music and musicians through themes of struggle helped participants feel more connected to the music and metal community, and for some, it even played a motivational role (e.g., If this musician can persist through their mental health struggles, then so can I). This is consistent with a recent study that found that health struggle narratives from idolized persons serve a positive function for the general public, resulting in increased levels of health examinations and seeking rehabilitation for ailments (Beck, Aubuchos, McKenna, Ruhl, \& Simmons 2014). However, the incorporation of mental health themes in metal music comes at a cost, since the lyrical content in metal music often exaggerates, fetishizes, or inaccurately portrays mental health disorders, as is the case of schizophrenia. The symptoms of participants had a complex relationship with metal music and culture, as symptoms were sometimes managed and alleviated through listening to music, help from concert participation, and social relatedness with other 
metal fans, particularly when managing anxiety, sadness, and resisting negative behaviors like self-harm according to participants' self-reports. This is consistent with past research showing the protective role of social support (Cohen \& Willis 1985). It is important to note, the extent to which metal music and culture helps with symptoms in our sample appears to be mitigated by the severity of their mental illness. In cases where symptoms are more severe, as is the case of schizophrenia, then symptoms were reported as not being alleviated by metal music or culture. However, those participants reported their severe symptoms as having an intensifying effect for the experience of listening to metal music. Lastly, participants communicated a desire for understanding from others about their ailments, and a desire for belonging that they felt was most readily fulfilled by metal music and culture.

This study outlines an extensively positive view of metal music and culture and its functions, which was expected as all data were drawn from self-reports from members of the metal community. It shouldn't be drawn from this study that these are objectively the functions of the metal community, but rather, this is the metal community as perceived by the participants in our sample. This level of positivity is expected from an in-group member speaking of their in-group.

One limitation of the study is its limited scope, as a small sample with a focus on a single music community was utilized, which limits the extent to which the results would apply to other music communities and non-music communities. Future studies could correct that by expanding into other communities, disciplines, and methodologies. That being said, this study can serve as a starting point for exploring the relationship that metal fans have with metal music, particularly among metal fans with mental and 
developmental disorders. People with mental health concerns are broadly represented in metal music culture, and that is likely due, in part, to metal culture being a community that is perceived as more welcoming for people with mental illness since it does not have the same stigmas towards mental illness as broader society.

\section{Future Directions}

Participants in this study reported using metal music to manage their emotions and in some cases, their symptomology. Future research could expand these findings by applying them in a clinical setting to see if the claims made by participants can be applied in the context of music therapy. Currently, music therapy interventions have been used with success in managing autism (Whipple 2004), dementia (Ueda, Suzukamo, Sato, \& Izumi 2013), depression, (Esfandiari \& Mansouri 2014; Maratos, Gold, Wang, \& Crawford 2008), schizophrenia (Mössler, Chen, Heldal, \& Gold 2011), and other serious mental disorders (Gold, Solli, Krüger, \& Lie 2009). Metal music has been used as a coping mechanism to deal with feelings of anger and loneliness as a result of battling cancer, and has even helped some find meaning in life (Ahmadi 2013), so it is hoped that music therapy interventions can be developed specifically with metal music fans in mind, as they are a large and global population with high rates of emotional vulnerability and mental health conditions. Since metal fans perceived lower levels of stigma in the metal community, they might be more likely to seek help in managing their symptoms, so future research could help facilitate a clear pathway for their mental health assistance. The role of subgenre-consistent music preferences in this study could be applied to developing music therapy treatments with a focus on members of the metal community. 


\section{Funding}

The authors received no financial support for the research, authorship, and/or publication of this article. 


\section{References}

Ahmadi, F. (2013), 'Music as a method of coping with cancer: A qualitative study among cancer patients in Sweden', Arts \& Health, 5:2, pp.152-165.

Amato, P. and Bradshaw, R. (1985), 'An exploratory study of people's reasons for delaying or avoiding helpseeking', Australian Psychologist, 20:1, pp.21-31.

American Psychiatric Association, (2013), Diagnostic and Statistical Manual of Mental Disorders (5th ed.), Washington, DC: Author.

Angeler, D. (2018), 'Analogies between heavy metal music and the symptoms of mental illness', Challenges, 9:1, pp.18.

Baker, F. and Bor, W. (2008), 'Can music preference indicate mental health status in young people?’, Australasian Psychiatry, 16:4, pp.284-288.

Beck, C., Aubuchon, S., McKenna, T., Ruhl, S. and Simmons, N. (2013), 'Blurring personal health and public priorities: An analysis of celebrity health narratives in the public sphere', Health Communication, 29:3, pp.244-256.

Belmaker, R. (2004), 'Bipolar disorder', New England Journal of Medicine, 351:5, pp.476-486.

Clarke, V. and Braun, V. (2016), 'Thematic analysis', The Journal of Positive Psychology, 12:3, pp.297-298.

Coggins, O. (2016). 'Transforming detail into myth: indescribable experience and mystical discourse in drone metal', Global Metal Music and Culture: Current Directions in Metal Studies, pp. 311-329.

Cohen, S. and Wills, T. (1985), 'Stress, social support, and the buffering hypothesis’, Psychological Bulletin, 98:2, pp.310-357.

Esfandiari, N. and Mansouri, S. (2014), 'The effect of listening to light and heavy music on reducing the symptoms of depression among female students', The Arts in Psychotherapy, 41:2, pp.211-213.

Gay, J. (2000), 'Moral boundaries and deviant music: public attitudes toward heavy metal and rap', Deviant Behavior, 21:1, pp.63-85.

Geretsegger, M., Mössler, K., Bieleninik, Ł., Chen, X., Heldal, T. and Gold, C. (2017), 'Music therapy for people with schizophrenia and schizophrenia-like disorders', Cochrane Database of Systematic Reviews, pp. 1-104.

Gold, C., Solli, H., Krüger, V. and Lie, S. (2009), 'Dose-response relationship in music therapy for people with serious mental disorders: Systematic review and metaanalysis', Clinical Psychology Review, 29:3, pp.193-207. 
Gross, R. (1990). 'Heavy metal music: A new subculture in American society', Journal of Popular Culture, 24:1, pp. 119-130.

Guibert, C. and Guibert, G. (2016). 'The social characteristics of the contemporary metalhead: the Hellfest survey.' In Andy R Brown, Karl Spracklen, Keith Kahn-Harris and Siall W.R. Scott (Eds.), Global metal music and culture: current directions in metal studies (pp 167-189). New York, New York: Routledge.

Hickam, B. (2014). 'Amalgamated anecdotes: Perspectives on the history of metal music and culture studies.' Metal Music Studies, 1:1, pp. 5-23.

Kahn-Harris (2007). Extreme metal: music and culture on the edge. Oxford: Berg.

Kushner, M. and Sher, K. (1991), 'The relation of treatment fearfulness and psychological service utilization: An overview', Professional Psychology: Research and Practice, 22:3, pp.196-203.

Maratos, A., Gold, C., Wang, X. and Crawford, M. (2008),' Music therapy for depression', Cochrane Database of Systematic Reviews, pp. 1-22.

Mason, O. and Daniels, H. (2018), 'Psychotic traits in musicians', Psychological Medicine, 48:12, pp.2096-2097.

Messick, K. and Aranda, B. (2020). 'The role of moral reasoning \& personality in explaining lyrical preferences’, PLOS ONE, 15:1: e0228057. https://doi.org/10.1371/journal.pone.0228057

Mulder, J., Ter Bogt, T., Raaijmakers, Q., Gabhainn, S., Monshouwer, K. and Vollebergh, W. (2009), 'The soundtrack of substance use: music preference and adolescent smoking and drinking', Substance Use \& Misuse, 44:4, pp.514-531.

Sharman, L. and Dingle, G.A., (2015), 'Extreme metal music and anger processing', Frontiers in Human Neuroscience, 9, p.1-11.

Spracklen, K., Brown, A., and Kahn-Harris, K. (2011). Metal studies? Cultural research in the heavy metal scene. Journal for Cultural Research, 15:3, pp. 209-212.

Ueda, T., Suzukamo, Y., Sato, M. and Izumi, S. (2013), 'Effects of music therapy on behavioral and psychological symptoms of dementia: A systematic review and metaanalysis', Ageing Research Reviews, 12:2, pp.628-641.

Ury-Petesch, J. (2016). The numbers of the beast: surveying Iron Maiden's global tribe. In Andy R. Brown, Karl Spracklen, Keith Kahn- Harris, \& Niall Scott (Eds.), Global metal music and culture: Current directions in metal studies (pp 145-166). Routledge.

Whipple, J. (2004), 'Music in intervention for children and adolescents with autism: A meta-analysis', Journal of Music Therapy, 41:2, pp.90-106. 
Wrigley, S., Jackson, H., Judd, F. and Komiti, A. (2005), 'Role of stigma and attitudes toward help-seeking from a general practitioner for mental health problems in a rural town', Australian and New Zealand Journal of Psychiatry, 39:6, pp.514-521. 